appropriate beneath a mid-ocean ridge (around $10^{-4} \mathrm{~m}^{3} \mathrm{~s}^{-1}$ per metre of midocean ridge) if the material in the channel had a viscosity and inferred buoyancy like that observed in the experiments. This example, although extreme, is in the spirit of previously proposed explanations for the focusing of crustal formation at midocean ridges $^{4,9}$.

But the biggest concern is the problem of scaling to mantle systems. The experimentally observed behaviour of the melt during deformation evidently disagrees with surface-energy minimization, suggesting that kinetics are important. But if kinetics (the speed with which melt can freeze or new melt can form at interfaces) are important, then how can we translate experiments that last only tens of hours into mantle conditions over tens of thousands to millions of years? Unless we understand how to do this, we are not entitled to assume that the experiments tell us what happens in the mantle. That is the challenge for the future.

David J. Stevenson, of the Division of Geological and Planetary Sciences, California Institute of Technology, is currently at the Research School of Earth Sciences, Victoria University of Wellington, PO Box 600 , Wellington, New Zealand.

\title{
Shattering egg shells
}

\section{Nicholas C. Fraser}

ONE of the staples of displays and popular books about dinosaurs will have to change. This is the picture of a baby ceratopian dinosaur Protoceratops hatching from its egg, with caring parents hovering in the background. The problem is that the scene depicts the wrong parents. As described in last week's Science ${ }^{1}$ by a team from the American Museum of Natural History and the Mongolian Academy of Sciences, an exquisitely preserved, mature embryo within one of these highly characteristic eggs is not a Protoceratops but a theropod dinosaur from the family Oviraptoridae - by definition one of the 'egg robbers' supposed to have dined on Protoceratops nests.

Ironically, it was discoveries by another American Museum field crew some 70 years earlier that resulted in the misconception. In 1922 the museum mounted an expedition, led by Roy Chapman Andrews, into Mongolia. The group's principal objective was to find mammal fossils, but the Gobi desert yielded incredible evidence of Upper Cretaceous dinosaurs (about 80-70 million years old), including both theropods and ornithischians. The jewels in the haul were undoubtedly the skeletons of the small ceratopian dinosaur Protoceratops and their putative eggs and nests. It was not unreasonable to suppose that the eggs were those of Protoceratops given the great abundance of protoceratopians, represented by various growth stages, and the extreme scarcity of theropods (the original collections from the Djadokhta Formation included 101 protoceratopians, but only four theropods in total, and only one oviraptorid). Over the years these finds have shaped many an exhibit and lecture.

The new material paints a very different picture. Moreover, to add a further gloss to the story, two skulls of very young (probably embryonic) dromaeosaurid theropods were found with the nest. (Dromaeosaurs were active predators, popularized as 'raptors' in Jurassic Park.) Once again the reason for the association is not immediately apparent. Given the relatively undisturbed nature of the whole nest it seems unlikely that the skulls arrived there by chance. Perhaps the dromaeosaurids also hatched in the nest; if so, this would be the first evidence to suggest that some dinosaurs had adopted the parasitic nest habit that is typified by cuckoos. Alternatively, their presence could have been the result of the parent oviraptorids ransacking a neighbouring dromaeosaur nest.

Although dinosaur eggs were known before the 1920 s, their occurrence had not been widely reported upon. Since then a number of such nests have been recovered from the Gobi desert, and with the discovery around the world of a number of other locations containing dinosaur eggs, research into this aspect of dinosaur palaeobiology has reached new heights ${ }^{2}$. The classification of fossil eggshell has now become quite refined, and is typically based upon a number of fairly well defined characteristics. Shell macromorphology (shape, size, surface sculpturing and thickness) and histostructural pattern (type of pore canal system, arrangement of different microlayers), and ethological characters (pattern of arrangement of eggs in the nest), are very precise and when used together define very specific egg types. There can be no question that the eggs described by Norell et al. ${ }^{1}$ are of exactly the same type as the numerous examples previously referred to protoceratopians. Their microstructure, with the angusticanaliculate pore system, is similar to that of ratite birds.

It now seems rather unfortunate that Henry Osborn gave Oviraptor philocera- tops ('egg thief with a desire for ceratopian eggs') that name; he did so because the first specimen was found with its head crushed against a nest of the supposed Protoceratops eggs $^{3}$. At the time it was postulated that a parent Protoceratops might have surprised the would-be thief, and exacted its revenge. In view of our current information this example of $\mathrm{Ovi}$ raptor may have been protecting or even incubating the eggs when it died, and we could add that a more suitable name might have been 'Oviraptor philodromaeosaur'. Alternatively this particular animal may have met its end plundering another oviraptorid nest.

Whatever the cause of death of this individual, there is no doubt that its short toothless jaws would have been efficient tools for breaking eggs (although some workers have suggested that oviraptors could just have easily been herbivores, drawing a parallel with the herbivorous dicynodonts of the Permian). But in the light of the latest evidence, the question of just why Protoceratops is found with the oviraptorid eggs must now be asked - is there some palaeoecological information that we have failed to spot, or is the association perhaps just sheer chance?

The new discovery serves to emphasize the point that taxonomic assignment of eggs can be certain only when they are found with intact embryos and hatchlings, as for instance in the case of the hadrosaur Maiasaurua and the hypsilophodont Orodromeus $^{4,5}$. The lesson of caution is one that has recently been well taught in the circles of vertebrate palaeontologists. For example the rich beds of the Chañares Formation of Argentina ${ }^{6}$ have produced a wonderful diversity of Triassic archosaurs; but in many cases skeletal elements are closely associated rather than completely articulated, and it has emerged that some taxa are in fact chimaeras of two separate forms. The smoking gun might be pointing in the wrong direction - we also need the ballistics report on the bullet to confirm our suspicions.

When we add the finds of Norell et al. ${ }^{1}$ to the discovery in 1992, also in the Djadokhta (and equivalent formations), of the curious flightless bird Mononychus $^{7}$, we have to ask what other treasures await us in Mongolia. We are in a golden age of dinosaur research, and I suspect that the best is yet to come.

Nicholas C. Fraser is at the Virginia Museum of Natural History, 1001 Douglas Avenue, Martinsville, Virginia 24112, USA.

1. Norell, M. A. etal. Science 266, 779-782 (1994).

2. Carpenter, K., Hirsch, K. F. \& Horner, J. R. (eds) Dinosaur Eggs and Babies (Cambridge Univ. Press, 1994)

3. Osborn, H. F. Am. Mus. Novit. 144, 1-12 (1924)

4. Horner, J. R. \& Makela R Nature 282 296-298(1979).

5. Horner, J. R. \& Weishampel D. B Nature 332, 256-257 (1988).

6. Romer, A. S. Breviora 395, 1-24 (1972),

7. Altangerel, P., Norell, M. A.. Chiappe, L. M. \& Clark, J Nature 362, 623-626 (1993) 